\title{
Comparative Genetics Using Three mtDNA Markers in Aedes aegypti (Linnaeus) Populations from Four Municipalities in the Satate of Mato Grosso, Brazil.
}

Sandra Mariotto ( $\sim$ sandra.mariotto@blv.ifmt.edu.br)

Instituto Federal de Educação, Ciência e Tecnologia de Mato Grosso

Mari Rose Oliveira Silva

Universidade de Cuiabá

Cristina Márcia Menezes Butakka

Universidade de Cuiabá

Lenicy Lucas Miranda Cerqueira

Universidade Federal de Mato Grosso

Rosina Djunko Miyazaki

Universidade Federal de Mato Grosso

Fabiana Aparecida Caldart Rodrigues

Universidade Estadual de Mato Grosso

\section{Research Article}

Keywords: Comparative Genetics, Three mtDNA Markers, Aedes aegypti (Linnaeus)

Posted Date: August 12th, 2021

DOl: https://doi.org/10.21203/rs.3.rs-785088/v1

License: (9) (i) This work is licensed under a Creative Commons Attribution 4.0 International License.

Read Full License 


\section{Abstract}

Aedes aegypti mosquito has spread throughout the tropical and subtropical world and is currently the primary species responsible for transmitting dengue, urban yellow fever, Chikungunya, and Zika virus. This study aimed to investigate the inter- and intrapopulational genetic variability of Aedes aegypti through mitochondrial DNA, COI, ND4, and ND5 molecular markers in four municipalities in Mato Grosso. We used the Geneious software to build dendrograms for differentiating populations from each municipality. The interpopulational genetic distance obtained from sequence analysis showed a difference within populations through groups' formation in the ordering. Besides, we identified a difference in the interindividual genetic distance values, notably for the ND5 gene from the populations captured in the four municipalities. We recorded the smallest interindividual genetic distance within populations for populations from Chapada dos Guimarães. Extrinsic factors, including breeding habitat removal, can contribute to decreasing variability. Consequently, the dendrogram showed some similarities. Ovitrap monitoring, vector elimination, and genetic flow investigation stimulate actions to prevent transmitted diseases and support essential effective measures to control and fight Ae. aegypti.

\section{Introduction}

Aedes (Stegomyia) aegypti mosquito (Linnaeus, 1762), a mosquito native to Africa ${ }^{1}$, has spread throughout tropical and subtropical areas due to anthropogenic activities. Today, Ae. aegypti is responsible for transmitting dengue, yellow fever, Chikungunya, and Zika virus infection. Dengue is currently one of the most frequent diseases in Brazil ${ }^{2}$. Its annual variations in reporting and expansion is directly related to several factors, such as favorable environment, new serotype circulation, human population movements, and vector local infestation level. For this reason, Ae. aegypti adaptation to urban environments favors anthropic long-distance dispersion, supported by the eggs' resistance to desiccation and human host ${ }^{3}$.

An alternative monitoring method of $A$ e. aegypti is the detection and quantification of eggs deposited in oviposition traps installed in the home environment, which allows the identification of areas with the presence of mosquitoes and the analysis of the spatial and temporal distribution of its population ${ }^{4}$. An essential tool in this vector's study is the capture employing ovitraps to control and monitor populations by obtaining a significant number of specimens. This tool provides information on the presence and population density in different environments that can be estimated using samples, based on genetic methods ${ }^{5}$. Population diagnosis of Ae. aegypti through ovitraps allows checking the presence of mosquitoes throughout the year by attracting the pregnant female to oviposition ${ }^{6}$. A study in China, which employed this capture method, showed that vector control is critical and sometimes the only effective way to block or decrease dengue transmission ${ }^{7}$. Infestations can increase according to higher temperatures, humidity ${ }^{8}$, and disordered urbanization. 
The genetic diversity of some South American populations have been assessed using a wide range of genetic markers. Mitochondrial DNA (mtDNA) genes are widely used for the identification of genetic variants, dispersal patterns, phylogeny, and population dynamic studies of Ae. Aegypti ${ }^{9,10}$. Besides the populational quantification of Ae. Aegypti, the literature reports the use of markers, including mitochondrial DNA ${ }^{4,11}$, especially the Cytochrome Oxidase I ( $\left.C O I\right)$ gene, widely used in culicid research, to analyze its genetic variability ${ }^{12}$. Molecular techniques, including the polymerase chain reaction (PCR), can contribute to the understanding of vector-human relationships and also enable the genetic study of populations ${ }^{13}$ and their diagnostic investigation in different biological samples ${ }^{14}$.

The evaluation of genetic diversity on a smaller scale, such as in cities, allows us to verify viral dispersion. Ae. aegypti genetic diversity analysis might be applied to know the structure of the populations to comprehend their dynamics, providing data that might lead to new control measures ${ }^{15}$. Several genetic mechanisms are known to generate variability within and between populations, whose differences can arise from random occurrences, including the genetic composition of specimens that disperse and create new populations ${ }^{16}$. In addition, there may be changes in allele frequencies resulting from occasional breeding in small ${ }^{17}$ or large populations, whose effect can be underestimated in short periods. Differences between populations under different environmental conditions for survival and reproduction (adaptive value ${ }^{18}$ ) can accumulate and result in the development of a new species ${ }^{19}$.

Mitochondrial DNA (mtDNA) is an excellent target for molecular analysis due to the absence of introns, haploid inheritance, and because it contains only genes associated with mitochondrial functions. mtDNA is used in population genetic analysis ${ }^{20}$ and traces a species' evolutionary history ${ }^{21}$. Interestingly, repair mechanisms for this molecule have not yet been described, which likely facilitates the accumulation of mutations and, consequently, the detection of intraspecific variations ${ }^{21}$. Base substitutions, mtDNA deletions, and tRNA-encoding gene translocations cause changes in gene order between phylogenetically related organisms ${ }^{22}$.

Given the above, studies on the genetic variability of mosquitoes transmitting prominent urban viruses are critical in warmer regions with favorable environments for Ae. aegypti proliferation, as in the state of Mato Grosso. Therefore, this research aimed to investigate the inter- and intra-populational genetic variability of this vector in four municipalities in Mato Grosso by using three mitochondrial DNA markers: COI, ND4, and ND5.

\section{Results}

\section{Genetic Distance with Dendrograms.}

Of the 400 specimens identified as Ae. aegypti, 169 underwent PCR using COI, ND4, and ND5 primers. However, due to the low annealing capacity, the amplifications occurred in about $30 \%$ for $\mathrm{CO}$ / primer, 
which had the lowest annealing rate (Table 1). The ND5 primer presented the best genetic variability results.

Through the Geneious application, we ordered the three primers to identify the different populations in each municipality. The dendrograms ordered the specimens' distance between the municipalities (interpopulational, Fig. 1) and within each municipality (intrapopulational, Fig. 2). We also observed that the obtained sequences had interindividual differences within populations, especially when considering each municipality's sampling location. The most distant specimens indicate that there is a genetically variation, which may arise from a transitory individual into this population.

Table 1

Number of post-sequencing samples from the four municipalities analyzed.

\begin{tabular}{|llll|}
\hline Municipalities & Primers & \\
\cline { 2 - 4 } & COI (F/R) & ND4 (F/R) & ND5 (F/R) \\
\hline Cuiabá & 7 & 11 & 10 \\
\hline Várzea Grande & 8 & 11 & 10 \\
\hline Santo Antônio do Leverger & 5 & 11 & 8 \\
\hline Chapada dos Guimarães & 7 & 10 & 11 \\
\hline Total & 27 & 43 & 39 \\
\hline
\end{tabular}

In the interpopulation analysis of the trees generated, we verified distances that only one specimen from the municipality of CB was significantly distant from the others. This finding was based on observations from the COI mitochondrial gene (Fig. 1). Similarly, one sample based on this gene in the municipality of VG. Lastly, for CP and SA municipalities, we did not observe any significant genetic distance among the evaluated specimens. However, intrapopulation analysis of these three genes together (Fig. 2) showed a significant distance, especially in VG municipality with COI gene.

\section{Genetic Distance by Analysis of Variance - ANOVA between Factors.}

We identified highly significant interpopulational genetic distance values between Ae. aegypti specimens in the different municipalities, especially for the $N D 5$ gene (Fig. 3). The values were: $C B\left(F_{2,25}=29003 ; p=\right.$ $0.0000)$, $V G\left(F_{2,26}=24492 ; p=0.0000\right), C P\left(F_{2,25}=76,577 ; p=0.00000\right)$ and $S A\left(F_{2,21}=50186 ; p=0.0000\right)$. In $\mathrm{CP}$, the ND4 gene presented the lowest interpopulational genetic distance among the analyzed specimens (Fig. 4A). Comparatively and significantly $\left(F_{6,97}=5.4826, p=0.00006\right)$, we considered the sequence of the three primers together between the four municipalities (Fig. 4B), and the municipality with the shortest distance was also CP. 
We considered intrapopulational differences in the genetic distance for each gene (Fig. 5). The most significant intrapopulational genetic distance was recorded for the $\mathrm{CO} /$ gene from specimens captured in the municipality of $\mathrm{CB}\left(\mathrm{F}_{2,25}=34562 ; \mathrm{p}=0.0000\right)$. The recording in the VG municipality was significant, with low variability for all primers $\left(F_{2,26}=34.069 ; p=0.000\right)$. In $C P\left(F_{2,25}=1169.2 ; p=0.000\right)$, the ND5 gene reached the highest genetic distance. We observed a trend of less variability in the ND5 gene in the intrapopulational genetic distance of specimens from the municipality of $S A\left(F_{2,21}=19.911 ; p=0.000\right)$.

\section{Gene polymorphisms and DNA sequencing.}

We sequenced the segments of the mitochondrial DNA COI, ND4, and ND5 genes using the Sanger method, whose factorial ANOVA results derived from nitrogenous bases sequencing for each gene. Based on the sequencing results of the three genes combined, the Kruskal-Wallis test demonstrated significant differences $\left(\mathrm{H}_{33.52}=69.53 ; \mathrm{p}=0.000\right)$ compared to the three genes analyzed and frequency values between genes (Fig. $5 ; F_{8,194}=245.24 ; p=0.000$ ). However, when we analyzed specimens from the four municipalities, the frequency values of adenine, thymine, cytosine, and guanine did not present significant differences (Fig. 5; $F_{9,396}=0.32682 ; p=0.966$ ).

Genetic diversity values were high $(h=0.702 ; p=0.015)$ for the four municipalities. Such analysis allowed us to identify the greatest genetic diversity, which indicated that the variation occurred within populations, with an FST value of 0.329 .

\section{Haplotipic analysis map using Median Joining.}

Based on genes COI, ND4, and ND5 a network haplotype of Ae. aegypti populations from Baixada Cuiabana has complemented this research (Fig. 6). Under this, $\mathrm{COI}$ was represented with a total number of mutations of S/Eta: 54, the variance of haplotype diversity: 0,01009, and nucleotide diversity, Pi: 0,02972 . For ND4, the number of polymorphic (segregating) sites was $S: 48$, the total number of mutations Eta: 61 and, the variance of Haplotype diversity: 0,00358; the Nucleotide diversity had the Pi: 0,03916 . In this same analysis for the ND5 gene, the number of polymorphic (segregating) sites was S: 19, the total number of mutations was Eta: 19 and, the variance of haplotype diversity: 0,00210 with nucleotide diversity, Pi: 0,00396.

\section{Discussion}

Our study is the first to investigate the genetic variability of Ae. aegyptipopulations in municipalities of Mato Grosso. We observed a genetic variation in COI, ND4, and ND5 mtDNA sequences between specimens per analyzed location, with inter- and intrapopulational genetic distance. These genes accumulate base substitutions in the mitochondrial genome most rapidly ${ }^{33}$. In this study, when 
populations analyzed together and by gene, the distance found unlikely represents populational fragmentation nor events that could significantly distance a representative sample of individuals.

Birungi and Munstermann ${ }^{26}$ investigated Ae. albopictus in Brazil and the United States and stated that the effect of genetic drift is more pronounced in mtDNA than in nuclear loci. The present study results showed variability in the inter- and intrapopulational genetic distance for the Ae. aegyptipopulations analyzed, notably for the ND5 gene in between municipalities' populations. Ae. aegypti specimen analysis confirmed that these markers are essential in population sampling.

The dispersal of mosquitoes over long distances only occurs passively (eggs and adults transported), which may explain the diversity of some haplotypes in different locations. The shortest genetic distance between genes was found for ND4 in specimens captured in CP, with an exception in one sample only. Ponce et al. ${ }^{10}$ compared Ecuadorian populations of Ae. aegypti from 17 sites and revealed the presence of only two haplotypes. The variations detected between ND5 gene sequences in the municipalities may indicate a genetic structure in Ae. aegypti resulting from several factors, including extinction and recolonization events, genetic drift, and geographical differentiation.

Interpopulational genetic distance values for the $\mathrm{COI}$ gene showed low variability in the municipalities. However, population genetic analyzes of Ae. aegypti performed by Lv et al. ${ }^{34}$ identified a relatively high degree of polymorphism in the COI and ND4 sequences in eight populations, which were divided into eleven haplotypes. In studies using ND4 primer by Scarpassa et al. ${ }^{35}$, the polymorphism values were higher for the nucleotides, the same as what we found, probably because in Ae. aegypti this gene is under most mutations in many samples. In some studies, distance isolation may not be significant, indicating that genetic distance is not always linked to geographic distance $\left(r=-0.1216\right.$ and $\left.p=0.755^{36}\right)$.

The genetic differentiation study of 15 populations from Maranhão ${ }^{37}$, based on the mitochondrial marker ND4, found 15 haplotypes among the polymorphic sites. It revealed that most of the variation $(58.47 \%)$ was found within populations. In our study, fewer haplotypes variations occurred using ND5 and confirmed the total separation per marker applied. Of the 71 distinct haplotypes, ND4 represented $41 \%$ of the variation, $\mathrm{COI}$ with $35 \%$, and ND5 with $24 \%$. Few haplotypes were evidenced with a high mutation rate or variation about the others, within the same gene. The ND4 gene had the smallest interpopulation genetic distance among the analyzed specimens, especially in the municipality of Cuiabá.

Regarding the four municipalities analyzed in this study, the populations had specimens that were distant because of the ND5 gene, as shown by the genetic diversity values $(h=0.702 ; p=0.015)$ and the FST value of 0.329 , which indicated more considerable intrapopulational variation. Highly significant genetic distances can suggest speciation events. We identified a difference in the interindividual genetic distance values, notably for the ND5 gene from the populations captured in the four municipalities. Thus, our results show a robust hypothesis that new morphospecies is adapted to local environmental conditions, although morphological data is still lacking to support this assumption. 
Specimens with the most considerable genetic distance may originate from distinct lineages from areas adjacent to the capture site or reflect the natural selection. They might also result from passive transport by human movement with vehicles and cargo ${ }^{38}$. Barbosa et al. ${ }^{39}$ mention that the passive dispersion of vectors found mainly in tires started due to the intense tire trade between the municipalities of the regions where the first outbreaks occurred (in the state of São Paulo), with subsequent dissemination. Thus, tires can become a severe problem for public health.

The species populations from other microhabitats introduced into adjacent areas may share polymorphisms within the same and between different populations. However, the local gene flow can also be stopped due to geographical barriers; thus, no new characteristics are shared ${ }^{40}$. In the present study, we found no significant barriers between populations with the highest genetic distance and intrapopulational variation.

The ordering using dendrograms with the highest genetic distance indicates the dissimilarity between some loci, as found for the ND4 gene in CP in the interpopulational analyses. Population-extrinsic factors, including breeding habitat elimination, may contribute to the low variability at some points, with some dendrogram similarity per analyzed gene. Eleven ND4 gene and 10 ND5 gene specimens formed a distinct group in the alignment of 28 individuals in the municipality of CB. Such formation confers distance and genetic variability between the specimens within the populations analyzed. Similarly, this observation was also present in the other investigated cities, and the ND5 gene presented variability between populations, which may be related to old and repeated introductions of the species into different habitats. This statement is supported by Seixas et al. ${ }^{3}$ in an article on the colonization and populational diversity of Ae. aegyption Madeira Island, Portugal.

In the municipality of $\mathrm{CB}$, we statistically recorded the highest intra-populational variability for the mitochondrial $\mathrm{COI}$ gene. With analyses of this gene, Van de Vossemberg et al. ${ }^{21}$ identified specimens in different groups formed in dendrograms. These results are in keeping with those from this study, which can imply intraspecific variation between Ae. aegypti specimens. According to Seixas et al. ${ }^{3}$, different specimens analyzed based on $\mathrm{CO} /$ exhibit greater vectorial competence than other populations with a single haplotype. The higher the genetic variability in these mosquitoes, the greater likelihood they will disperse viruses and other disease-causing parasites.

Factorial ANOVA results for the investigated genes of each Ae. aegypti specimen showed the differences derived from variations between populations, leading to a genetic distance within each municipality. In general, the populations' genetic profile varies by place throughout the distribution of a species. These differences can arise from random occurrences, including the genetic composition of specimens that disperse and create a new population ${ }^{14}$.

Population-intrinsic changes can suggest the influence of genetic distance, with the consequent genetic drift of rare or restricted genes to a single population or geographically close populations, as the municipalities of CB and VG. More considerable genetic distances between specimens for the ND5 gene 
in these municipalities can be associated with multiple introductions linked to different strains, as their habitats have high movement of people, passive dispersion patterns, and infestation control activities.

Based on nucleotide differences and sequencing, given the nitrogenous base proportionality, molecular markers did not show differences between the municipalities through the Kruskal-Wallis Test (analysis performed using the joint gene sequences). The differences were present only in the base frequency between the encoded genes. The polymorphism among Ae. aegypti population was greater for the ND4 gene, with a greater number of mutations and nucleotide diversity, according to the results of the haplotype network such as the template proposed by Bandelt et al. (1999) and Rozas et al. (1999). Certain specimens of Ae. aegypti may be more similar to each other when using COI and ND5 primers.

Scarpassa et al. ${ }^{35}$ researched in fourteen locations in Brazil, including the Cuiabá city, using mitochondrial gene Cytochrome Oxidase I (COI) to examine gene flow among 163 mosquitoes from 14 cities. Phylogenetic analysis identified two clades in genetic variability. They recorded two types of haplotypes and found a significant polymorphism among other loci. These authors' analysis revealed two strains separated by 8 fixed mutations, suggesting that Ae. aegypti populations likely came from eastern and western Africa, with evidence of multiple introductions.

Our findings complement those results of earlier studies and have significant implications for understanding how these mosquitoes behave under distinct environments and, under human interventions. Therefore, the monitoring of Ae. aegyptispecies is essential for preventing and controlling vector-borne infectious diseases and, governments need to designate effective control measures, how mentioned by Lv et al ${ }^{34}$. Our principal limitation was, less than $20 \%$ of de DNA samples had been amplified using the primer $\mathrm{CO}$ of distinct populations (see material and methods) and, the authors suggest another's primers need to be designed for Brazilian populations of Ae. aegypti.

In conclusion, this pioneering study conducted in the state of Mato Grosso shows the intrapopulation diversity of Ae. aegypti in each municipality investigated. The monitoring with ovitraps and genetic research of Ae. aegypti aims to identify genetic variations to boost actions to prevent diseases transmitted by this species. Genetic flow and dispersion estimates can support the government's measures that are essential to effectively control and fight the vector.

\section{Material And Methods}

\section{Sampling and data.}

This study was carried out in four municipalities in the state of Mato Grosso: Cuiabá (CB), Várzea Grande (VG), Chapada dos Guimarães (CP), and Santo Antônio do Leverger (SA) (Fig. 7). We selected such regions due to their higher human population movement (CB and VG), distinct geographical position and altitude (SA, at about $100 \mathrm{~m}$, and $\mathrm{CP}$, at about 700 meters above sea level). The number of adults resulting from the development of eggs in the laboratory are shown in table 2. 
This was a descriptive observational study with a quantitative and qualitative approach. Data were collected with the aid of ovitraps during December/2015 (flooding), February/2016 (flood), June/2016 (drought), and November/2016 (flood) to investigate the number ( $n$ ) of copies of Ae. aegypti in the four municipalities (Table 2).

\section{Table 2}

Number of adults resulting from the development of eggs in the laboratory. Source: IFBIOTEC Laboratory/IFMT/Cuiabá MT.

\begin{tabular}{|ll|}
\hline Month/Year & Aedes aegypti samples \\
\hline December/2015 & 135 \\
\hline February/2016 & 355 \\
\hline June/2016 & 243 \\
\hline November/2016 & 374 \\
\hline Grand Total & 1,107 \\
\hline
\end{tabular}

To install the ovitraps, we selected three sampling points with a high movement of people in each municipality, as recommended by Fay and Eliason ${ }^{23}$. We counted the eggs in a stereomicroscope and kept them in the laboratory for hatching and maintenance up to adulthood. We relied on relevant literature to identify adult specimens ${ }^{24}$. Then, we placed specimens in polypropylene tubes containing $100 \%$ ethanol and labeled and stored them in a freezer $\left(-20^{\circ} \mathrm{C}\right)$. Individual DNA extraction from $400 \mathrm{Ae}$. aegypti specimens followed the manufacturer's protocol for insect DNA (Invisorb Spin Tissue Mini Kit). DNA quantification analysis was carried out after electrophoresis in 1\% agarose gel submerged in Tris-BorateEDTA buffer (1x) and Nano Spectrophotometer (Denovix D5). Subsequently, we amplified 169 samples with the best DNA result using primers for mitochondrial DNA (mtDNA): Cytochrome Oxidase subunit I (COI- F and R: Paduan and Ribolla 2008), Nicotinamide Adenine Dinucleotide Dehydrogenase Subunit 4 $\left(N D 4-F\right.$ and $\mathrm{R}^{25}$ ) and Nicotinamide Adenine Dehydrogenase Subunit 5 (ND5 - F and $\mathrm{R}^{26}$ ). After amplification and purification, the genes underwent Sanger sequencing. We deposited the sequences on the National Center for Biotechnology Information (GenBank, www.ncbi.nlm.nih.gov) under access number (available after acceptance of the article).

We analyzed the sequencing data for COI, ND4, and ND5 genes using SeqTrace, Mega, and Geneious applications (available online and Trial version, respectively). SeqTrace was used to perform DNA strand consensus; Mega for DNA sequence, distance, and dendrogram analysis; and Geneious was used to perform sequence cutting and alignment. We checked the sequences manually using Bioedit Sequence Alignment Editor 7.0.5.2 in ${ }^{29}$ Geneious ${ }^{\circledR}{ }^{27}$ Muscle software ${ }^{28}$. We checked substitution saturation (transitions and transversions) of nucleotide sequence through $\mathrm{DAMBE}^{30}$. The inter- and intraspecies 
genetic distance was determined through Kimura 2-parameter (K2P) using the nucleotide replacement model $^{31}$ in MEGA v6.0 $0^{32}$.

We tested the independent variables (variable $X$ - sampling locations and collection months) and dependent variables (variable $Y$ - PCR results) through:

a) analysis of variance (ANOVA) to verify the significance of data variability;

b) test for mean comparison, which consists of the smallest significant difference and amplitude of data distribution; and

c) Kruskal-Wallis test (Trial version) - a multiple comparisons test -, consisting of the average between samples in the gene and base variability between populations from the municipalities. We applied

d) this test for ANOVA treatments as the results of this analysis were significant.

We applied factorial ANOVA considering the interindividual genetic distance data based on dendrogram results per municipality. We considered gene factors ( $C O I, N D 4$, and ND5) as independent variables and genetic distance as the dependent variable (factorial). The factors 'genes' and 'municipalities' were analyzed jointly using two-way ANOVA together with nitrogenous base proportionality. We used Ae. albopictus as an external group and identified significant differences between each primer for the two vector species $\left(F_{1,119}=32,962 ; p=0.000\right)$. Haplotypic diversity calculation was performed using the DNAsp 6.0 program and, haplotic maps were made by Median Joining in the NETWORK 10 program (41, 42).

\section{Declarations}

\section{Acknowledgements}

This research was funded by FAPEMAT Fundação de Amparo à Pesquisa do Estado do Mato Grosso (Process 0316549/2018) by financial support (Edital PPSUS-2013-MS / CNPq / FAPEMAT / SES).

\section{Authors contributions}

Sandra Mariotto: coordinator of project, conducted all sample collections and the research on the genetic laboratory. Responsible accountable for all aspects of the work, and that manuscript in all steps.

Mari Rose de Oliveira Silva: applied primers to obtain sequences on genetic, and wrote a preview of this manuscript.

Cristina Marcia de Menezes Butakka: contributed to writing a preview of this manuscript, too to all statistical analysis, and revising it critically. 
Lenicy Lucas de Miranda Cerqueira: Helped to sample collections, contributed to all of this manuscript.

Rosina Djunko Miyazaki: Helped to sample collections, contributed to all versions of this manuscript.

Fabiana Aparecida Caldart Rodrigues: Helped with genetics analysis and, revising this manuscript.

\section{Competing interests}

The authors declare no competing interests.

\section{References}

1. Paupy, C. et al. Genetic structure and phylogeography of Aedes aegypti, the dengue and yellow-fever mosquito vector in Bolivia. Infect. Genet. Evol, 12, 1260-1269 (2012).

2. Ministério da Saúde. Monitoramento dos casos de arboviroses urbanas transmitidas pelo Aedes (dengue, chikungunya e Zika). Boletim Epidemiológico. Semanas Epidemiológicas 1 a 7. Vol. 51 $\mathrm{N}^{0} 10(2020)$.

3. Seixas, G. et al. Aedes aegypti na llha da Madeira (Portugal): variação genética de um vetor de dengue recentemente introduzido.Mem. Inst. Oswaldo Cruz.108 (1) (2013).

4. Degener, C. M. et al. \& Eiras, Á. E. Temporal abundance of Aedes aegypti in Manaus, Brazil, measured by two trap types for adult mosquitoes. Mem. Inst. Oswaldo Cruz, 109 (8), 1030-1040 https://doi.org/10.1590/0074-0276140234 (2014).

5. Filipović, l. et al. Using spatial genetics to quantify mosquito dispersal for control programs. BMC Biology(2020) 18:104. https://doi.org/10.1186/s12915-020-00841-0 (2020).

6. Miyazaki, R. D., Ribeiro, A. L. M., Pignatti, M. G., Junior, J. H. C. \& Pignati, M. Monitoramento do mosquito Aedes aegypti (Linnaeus, 1762) (Diptera: Culicidae), por meio de ovitrampas no Campus da Universidade Federal de Mato Grosso, Cuiabá, Estado de Mato Grosso.Rev. Soc. Bras. Med. Trop. julho/agosto.42 (4) (2009).

7. Li, Y. et al. Comparative evaluation of the efficiency of the BG-Sentinel trap, CDC light trap and Mosquito-oviposition trap for the surveillance of vector mosquitoes. Parasites \& Vectors, 9, 446 10.1186 / s13071-016-1724-x (2016).

8. Santos, D. A. S., Rodrigues, J. Z., Olinda, R. A. \& Goulart, L. S. Relação das variáveis climáticas com os casos de dengue em um município do interior de Mato Grosso dos anos 2001 a 2015. Multitemas, Campo Grande, MS 2018 set/dez; 23 (55): 5-24 (2018).

9. Jaimes-Dueñez, J., Arboleda, S., Triana-Chávez, O. \& Gómez-Palacio, A. Spatio-temporal distribution of Aedes aegypti (Diptera: Culicidae) mitochondrial lineages in cities with distinct dengue incidence rates suggests complex population dynamics of the dengue vector in Colombia. PLoS Negl. Trop. Dis, 9, e0003553 (2015). 
10. Ponce, P. et al. Two Haplotypes of Aedes aegypti Detected by ND4 Mitochondrial Marker in Three Regions of Ecuador. Insects, 12, 200 (2021). https://doi.org/10.3390/ insects12030200

11. Steffler, L. M. et al. Genetic variability and spatial distribution in small geographic scale of Aedes aegypti (Diptera: Culicidae) under different climatic conditions in Northeastern Brazil. Parasites \& Vectors, 9, 530 https://doi.org/10.1186/s13071-016-1814-9 (2016).

12. Naim, D. M., Kamal, N. Z. M. \& Mahboob, S. Population structure and genetic diversity of Aedes aegypti and Aedes albopictus in Penang as revealed by mitochondrial DNA cytochrome oxidade I. Saudi Journal of Biological Sciences, 27, 953-967 (2020).

13. Paduan, K. S. \& Ribolla, P. E. M. Characterisation of eight single nucleotide polymorphism markers in Aedes aegypti. 9 (1):114-116. https://doi.org/10.1111/j.1755-0998.2008.02282.x (2009).

14. Hiragi, C. et al. Variabilidade genética em populações de Aedes aegypti (L.) (Diptera: Culicidae) utilizando marcadores de RAPD. Neotrop. Entomol, 38 (4), 542-547 (2009).

15. Lopes, T. B. F. et al. Genetic study in Aedes (Stegomyia) aegypti (Linnaeus, 1762) from Londrina (Paraná State, Brazil): an approach to population structure and pyrethroid resistance. Revista Brasileira de Entomologia, 65 (1), e20200088 (2021).

16. Salgueiro, P. \& Abecasis, A. Aedes aegypti in Cape Verde: analysis of the mitochondrial gene IOC. In: Proceedings of the 2nd National Congress of Tropical Medicine; 2013 April: 20-23 (2013).

17. Lequime, S., Fontaine, A., Gouilh, M. A., Moltini-Conclois, I. \& Lambrechts, L. Genetic Drift, Purifying Selection and Vector Genotype Shape Dengue Virus Intra-host Genetic Diversity in Mosquitoes.PloS Genetics. (15):1-24(2016).

18. Gloria-Soria, A. et al. Global Genetic Diversity of Aedes aegypti. Mol Ecol. nov, 25 (21), 5377-5395 (2016).

19. Salgueiro, P. et al. Phylogeography and invasion history of Aedes aegypti, the Dengue and Zika mosquito vector in Cape Verde islands (West Africa).Evolutionary Applications(12):17971811(2019).

20. Camargo, A., González, D. \& Suárez, N. Mitochondrial DNA of the dengue' mosquito vector Aedes aegypti (Diptera: Culicidae) in Rivera city, Northern Uruguay. Boletim da Sociedad del Uruguay, 28 (1), 33-37 (2019).

21. Van de Vossemberg, B. T. L. H. et al. Real-time PCR Tests in Dutch Exotic Mosquito Surveys; Implementation of Aedes aegypti and Aedes albopictus Identification Tests, and the Development of Tests for the Identification of Aedes atropalpus and Aedes japonicus japonicus (Diptera: Culicidae). J. Med. Entomol, 52 (3), 336-350 (2015).

22. Schmidt, H. et al. Complete mitogenome sequence of Aedes (Stegomyia) aegypti derived from field isolates from California and South Africa. Mitochondrial DNA Part B, 3 (2), 994-995 https://doi.org/10.1080/23802359.2018.1495117 (2018).

23. Fay, R. W. \& Eliason, D. A. A preferred oviposition site as surveillance method for Aedes aegypti. Mosquito News, 26, 531-535 (1966).

24. Forattini, O. P. Culicidologia Médica. São Paulo, EDUSP. v. 2. 864p(2002). 
25. Paduan, K. S., Ribolla, P. E. M. \& Mitochondrial, D. N. A. Polymorphism and Heteroplasmy in Populations of Aedes aegypti in Brasil. Journal of Medical Entomology, 45, 59-67 DOI: 10.1603/0022-2585(2008)45[59:MDPAHI]2.0.CO;2 (2008).

26. Birungi, J. \& Munstermann, L. E. Genetic Structure of Aedes albopictus (Diptera: Culicidae) Populations Based on Mitochondrial ND5 Sequences: Evidence for an Independent Invasion into Brazil and United States. Bio One. Research Evolved. Annals of the Entomological Society of America, 95 (1), 125-132 (2002).

27. Kearse, M. et al. Geneious Basic: An integrated and extendable desktop software platform for the organization and analysis of sequence data., 28 (12), 1647-1649 (2012).

28. Hall, T. A. BioEdit: a user-friendly biological sequence alignment editor and analysis program for Windows 95/98/NT. Nucl Acids Symp Ser, 41, 95-98 (1999).

29. Edgar, R. C. Muscle: multiple sequence alignment with high accuracy and high throughput. Nucleic Acids Res, 32 (5), 1792-1797 (2004).

30. Xia, X., Xie, Z. \& Li, W. H. Effects of GC content and mutational pressure on the lengths of exons and coding sequences. J Mol Evol, 56, 362-370 (2003).

31. Kimura, M. A simple method for estimating evolutionary rates of base substitutions through comparative studies of nucleotide sequences. Journal of Molecular Evolution, 16, 111-120 (1980).

32. Tamura, K., Stecher, G., Peterson, D., Filipski, A. \& Kumar, S. Mega6: Molecular Evolutionary Genetics Analysis version 6.0. Molecular Biology and Evolution, 30, 2725-2729 (2013).

33. Costa-da Silva, A. L., Capurro, M. L. \& Bracco, J. E. Genetic lineages in the yellow fever mosquito Aedes (Stegomyia) aegypti (Diptera: Culicidae) from Peru. Memórias do Instituto Oswaldo Cruz. Rio de janeiro, 100 (6), 539-544 (2005).

34. Lv., R. C. et al. Genetic diversity and population structure of Aedes aegypti after massive vector control for dengue fever prevention in Yunnan border areas. Sci. Rep, (10), 12731 https://doi.org/10.1038/s41598-020-69668-7 (2020).

35. Scarpassa, V. M., Cardoza, T. B. \& Cardoso, R. P. Population genetics and phylogeography of Aedes aegypti (Diptera: Culicidae) from Brazil. American Journal of Tropical Medicine and Hygiene, 78, 895-903 (2008).

36. Twerdochlib, A. L. et al. Genetic variability of a population of Aedes aegypti from Paraná, Brazil, using the mitochondrial ND4 gene. Revista Brasileira de Entomologia, 56 (2), 249-256 (2012).

37. Sousa, A. A., Fraga, E., Sampaio, I., Schneider, H. \& Barros, M. C. Genetic differentiation in populations of Aedes aegypti (Diptera, Culicidae) dengue vector from the Brazilian state of Maranhão. Revista Brasileira de Entomologia, 61, 51-59 (2017).

38. Ministério da Saúde: Fundação Nacional de Saúde. Dengue - Instruções para pessoal de combate ao vetor: manual de normas técnicas. 3a. edição revisada. Brasília, 84 p. (2001).

39. Barbosa, G. L. et al. Influência de pontos estratégicos na dispersão de Aedes aegypti em áreas infestadas. Revista de Saúde Pública, 53, 29 (2019). 
40. Fraga, E. C. et al. Genetic variability and evidence of two distinct lineages of Aedes aegypti (Diptera, Culicidae) on São Luís Island in Maranhão, Brazil. Open Trop. Med. J, 6, 11-18 (2013).

41. Bandelt, H-J., Forster, P. \& Röhl, A. Median-joining networks for inferring intraspecific phylogenies. Mol Biol Evol, 16, 37-48 (1999).

42. Rozas, J. et al. \& Sánchez-Gracia, A. DnaSP 6: DNA Sequence Polymorphism Analysis of Large Datasets. Mol. Biol. Evol, 34, 3299-3302 https://doi.org/10.1093/molbev/msx248 (1999).

\section{Figures}




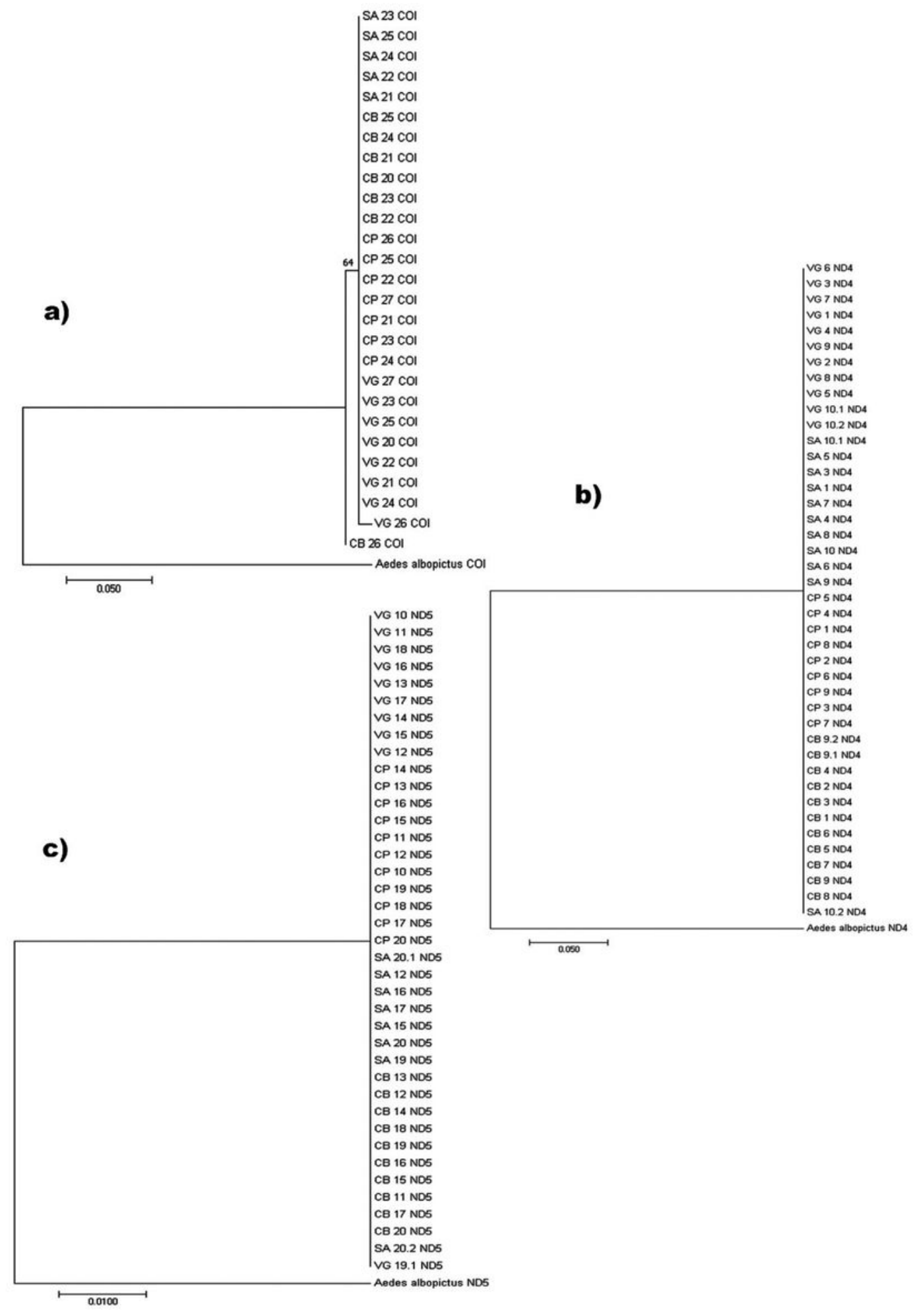

Figure 1

Dendrogram for the interpopulational analysis based on A) COI, B) ND4, and C) ND5 genes from Ae. aegypti populations recorded in the four municipalities. We used Ae. albopictus as an outside group for each primer. Legend 2. CB- Cuiabá; VG- Várzea Grande; CP- Chapada dos Guimarães, SA-Santo Antônio do Leverger. 
a)

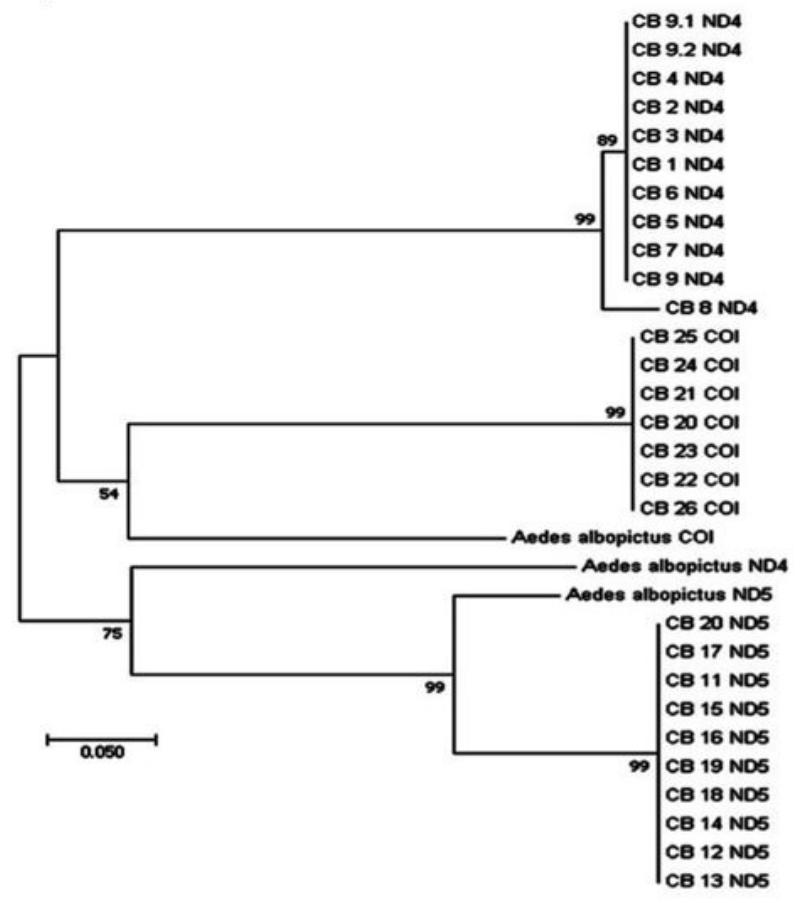

c)

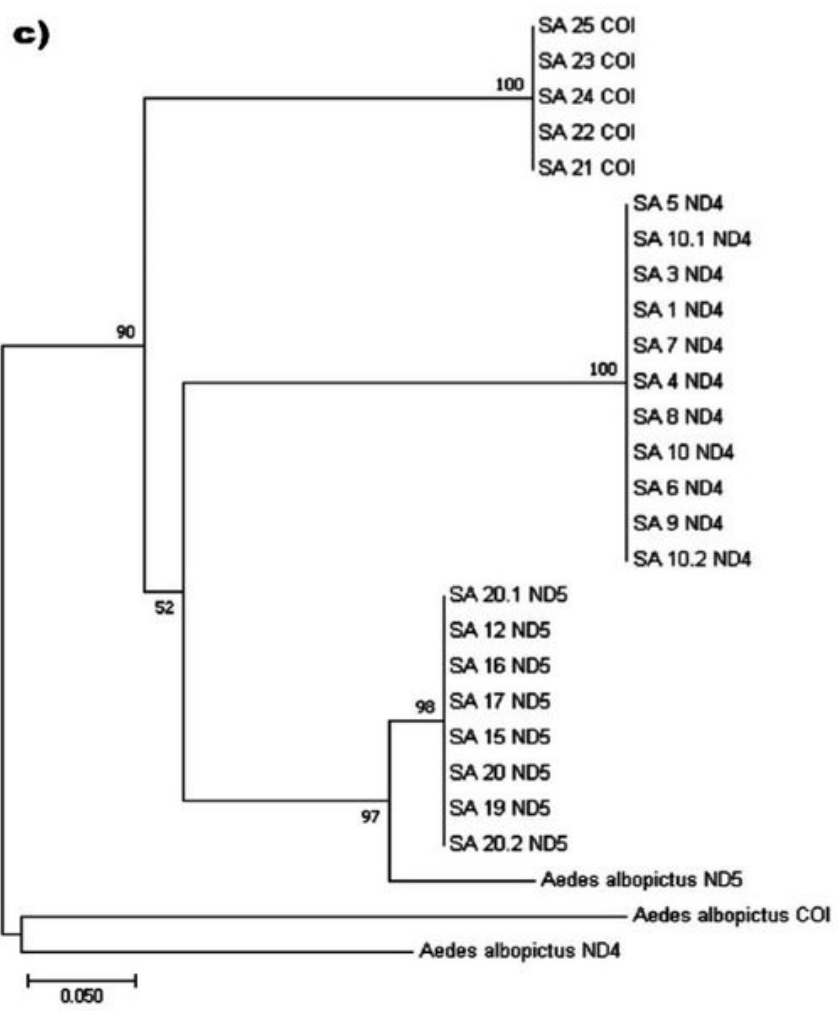

b)

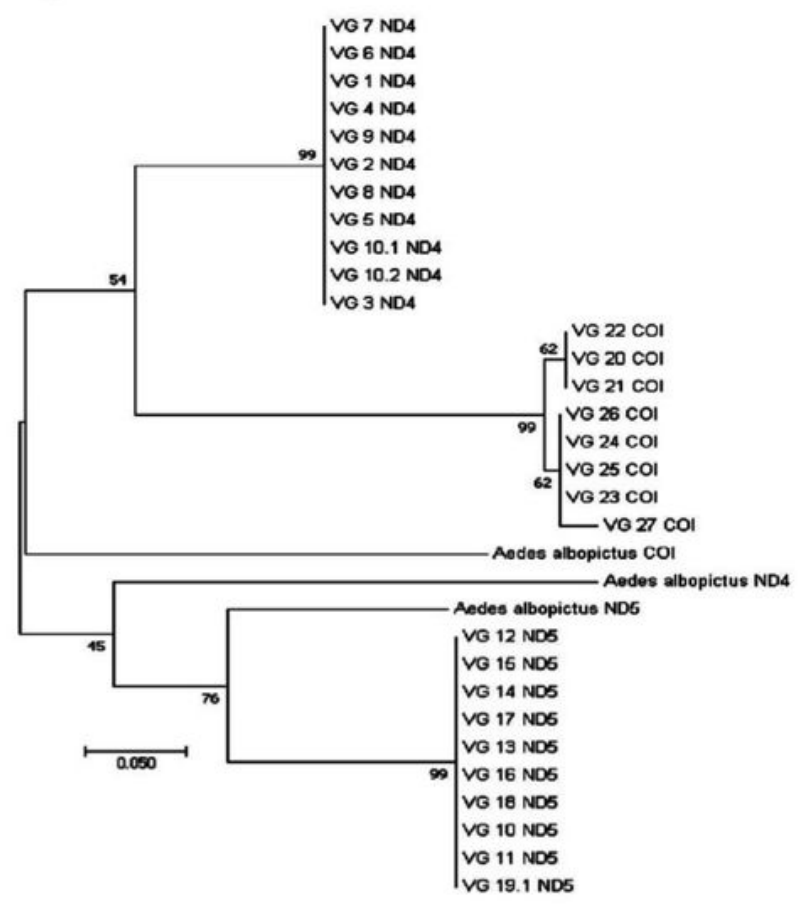

d)

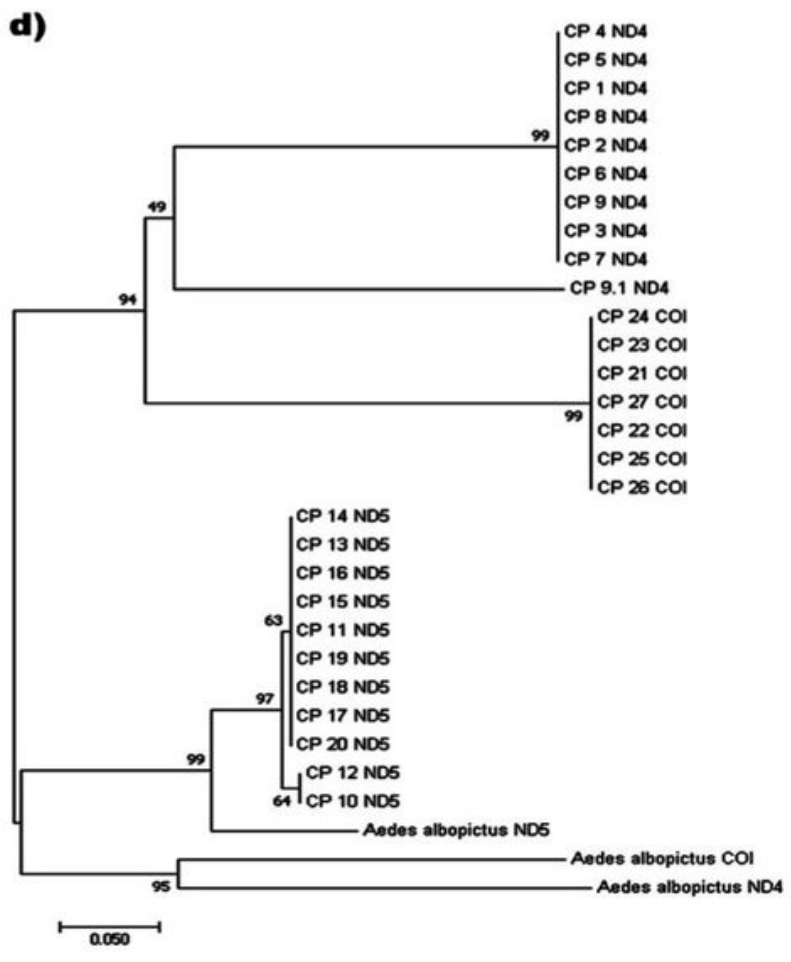

\section{Figure 2}

Dendrogram for intrapopulational analysis based on the results for COI, ND4, and ND5 genes from Ae. aegypti populations recorded in the four municipalities. We used Ae. albopictus as an outside group, using the results for each primer. Legend 3. A) CB- Cuiabá; B) VG- Várzea Grande; C) SA- Santo Antônio do Leverger; D) CP- Chapada dos Guimarães. 
CB

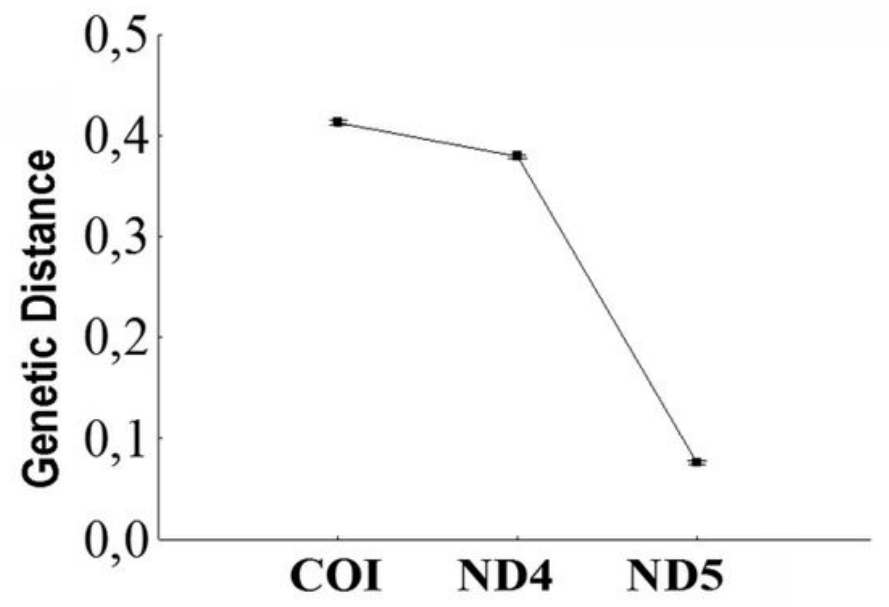

CP

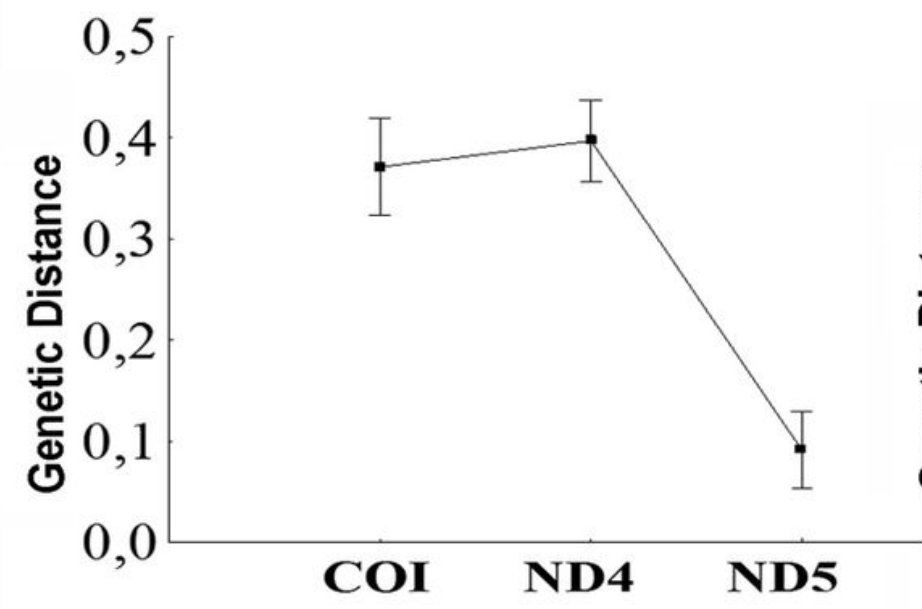

VG

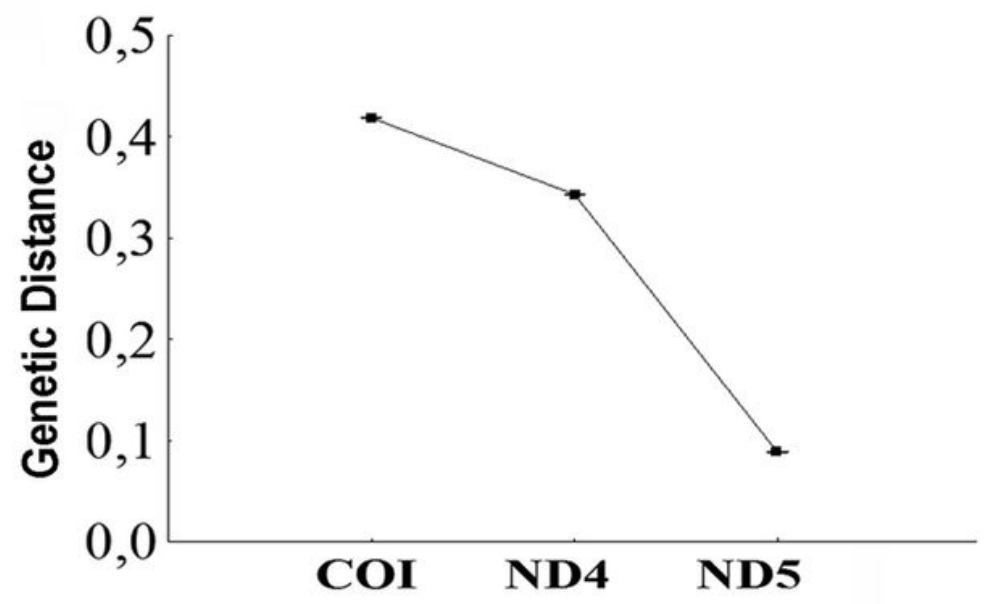

SA

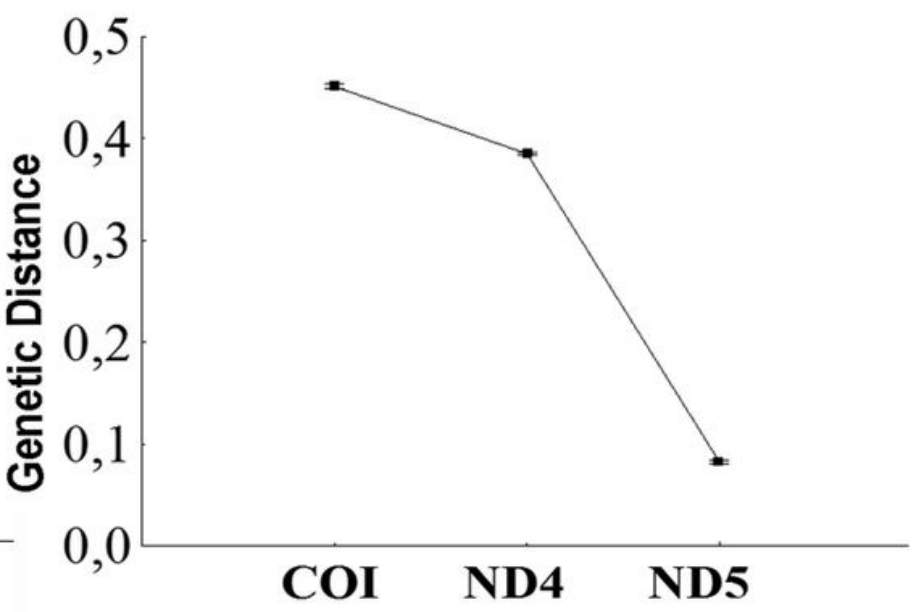

Figure 3

Specimens' interpopulational genetic distance mean values (standard deviation) for each gene (COI, ND4 and ND5), generated based on the dendrogram, municipalities of Cuiabá (CB), Várzea Grande (VG), Chapada dos Guimarães (CP), and Santo Antônio do Leverger/MT (SA). 

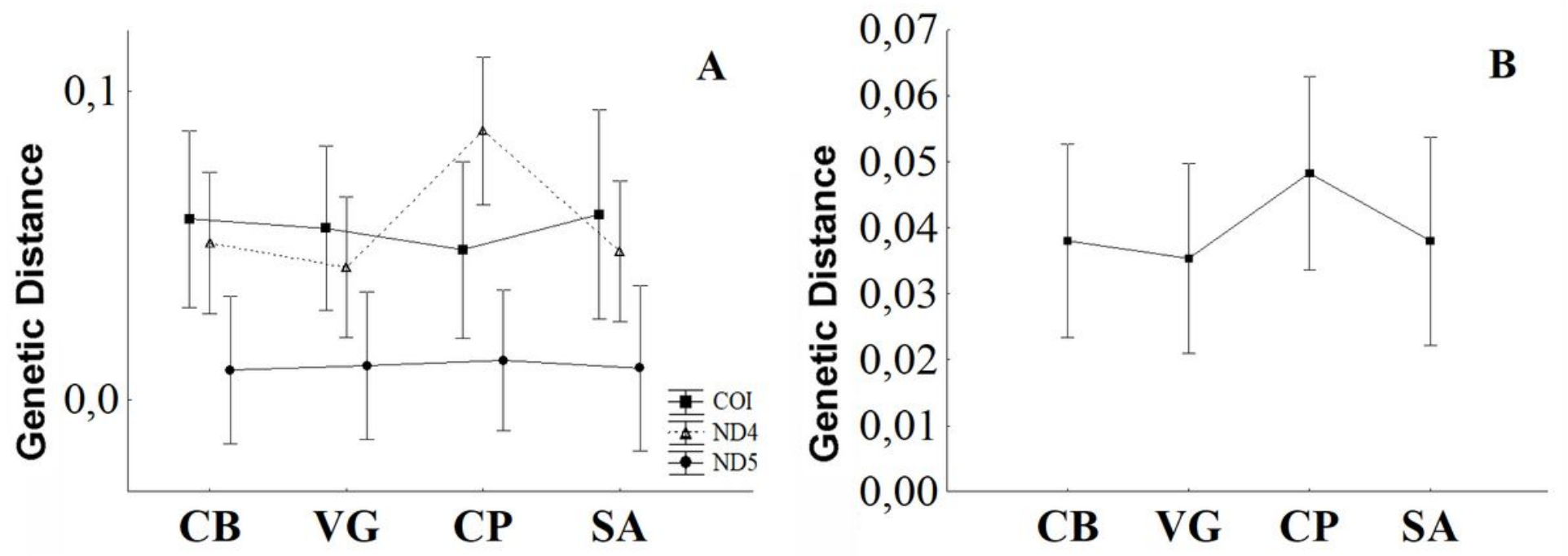

Figure 4

Specimens' interpopulational genetic distance mean values (standard deviation) for each gene $(A)$ and all primers generated (B) based on the dendrogram between the 4 municipalities analyzed. Legend: Cuiabá (CB), Várzea Grande (VG), Chapada dos Guimarães (CP), and Santo Antônio do Leverger/MT (SA). 
CB

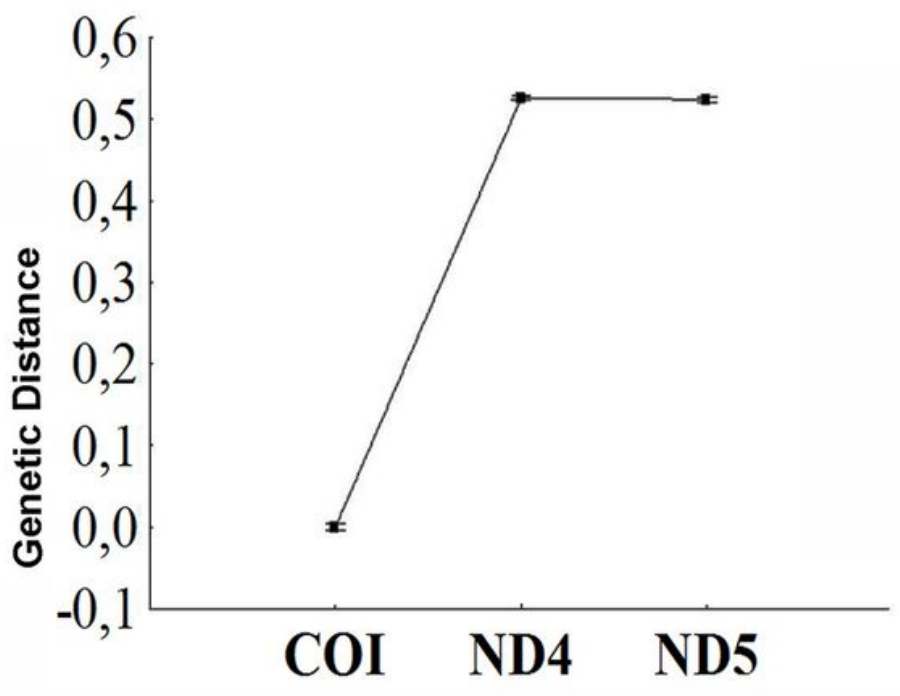

CP

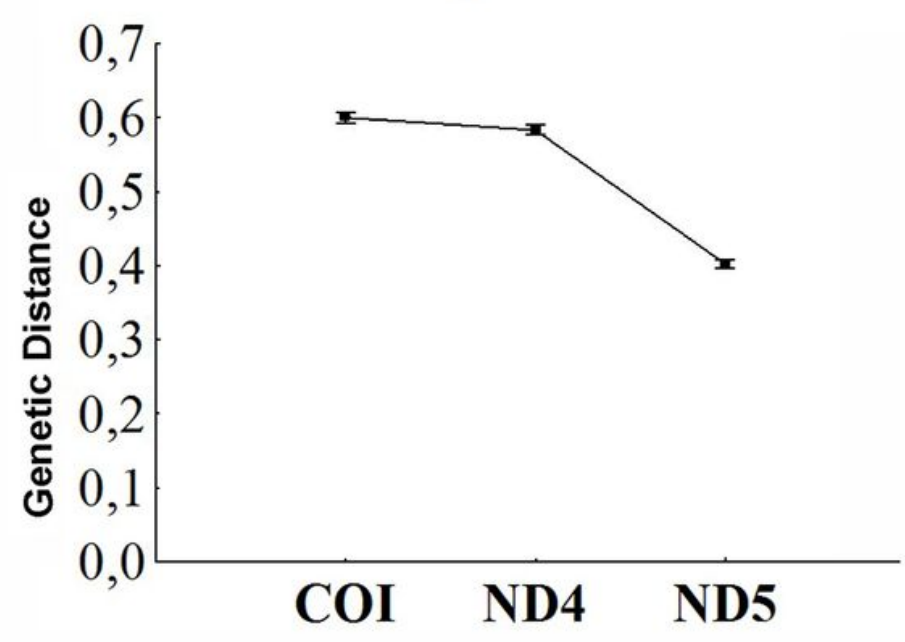

VG

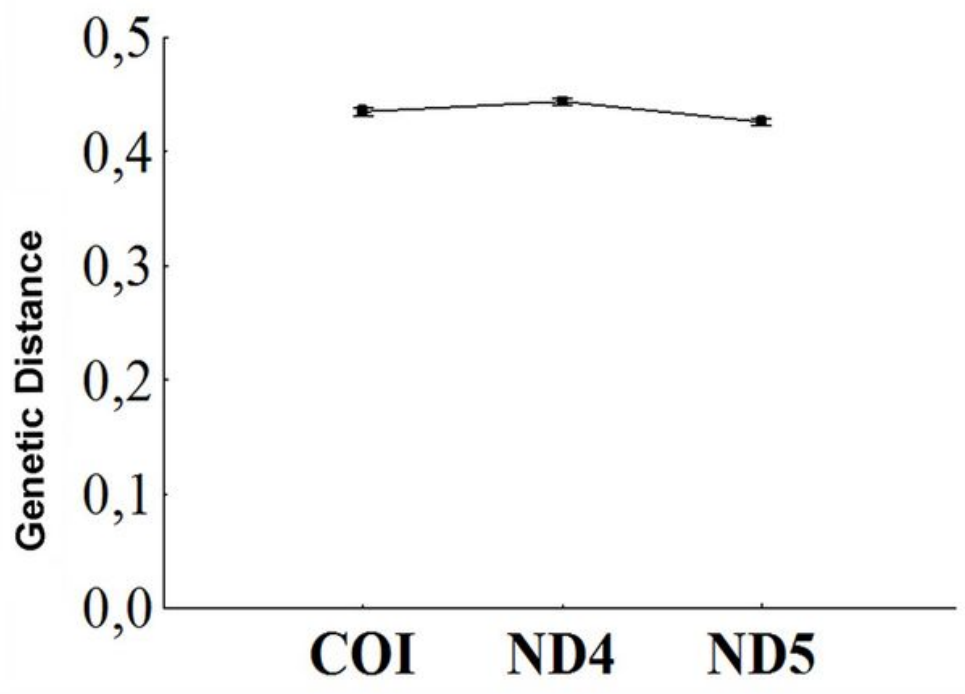

SA.

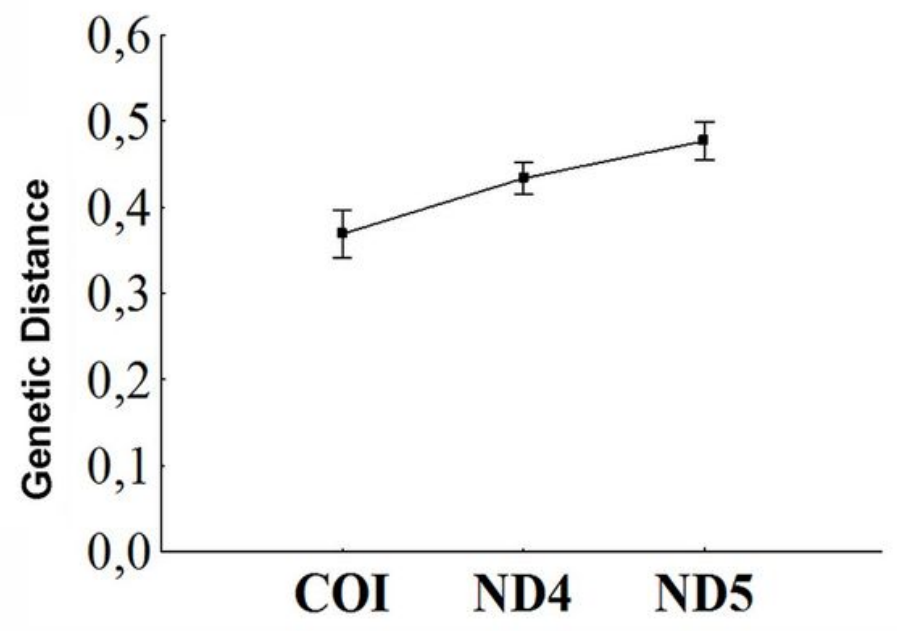

Figure 5

Specimens' intrapopulation genetic distance mean values (standard deviation) for each gene (COI, ND4, and ND5), generated based on the dendrogram, municipalities of Cuiabá (CB), Várzea Grande (VG), Chapada dos Guimarães (CP), and Santo Antônio do Leverger/MT (SA). 


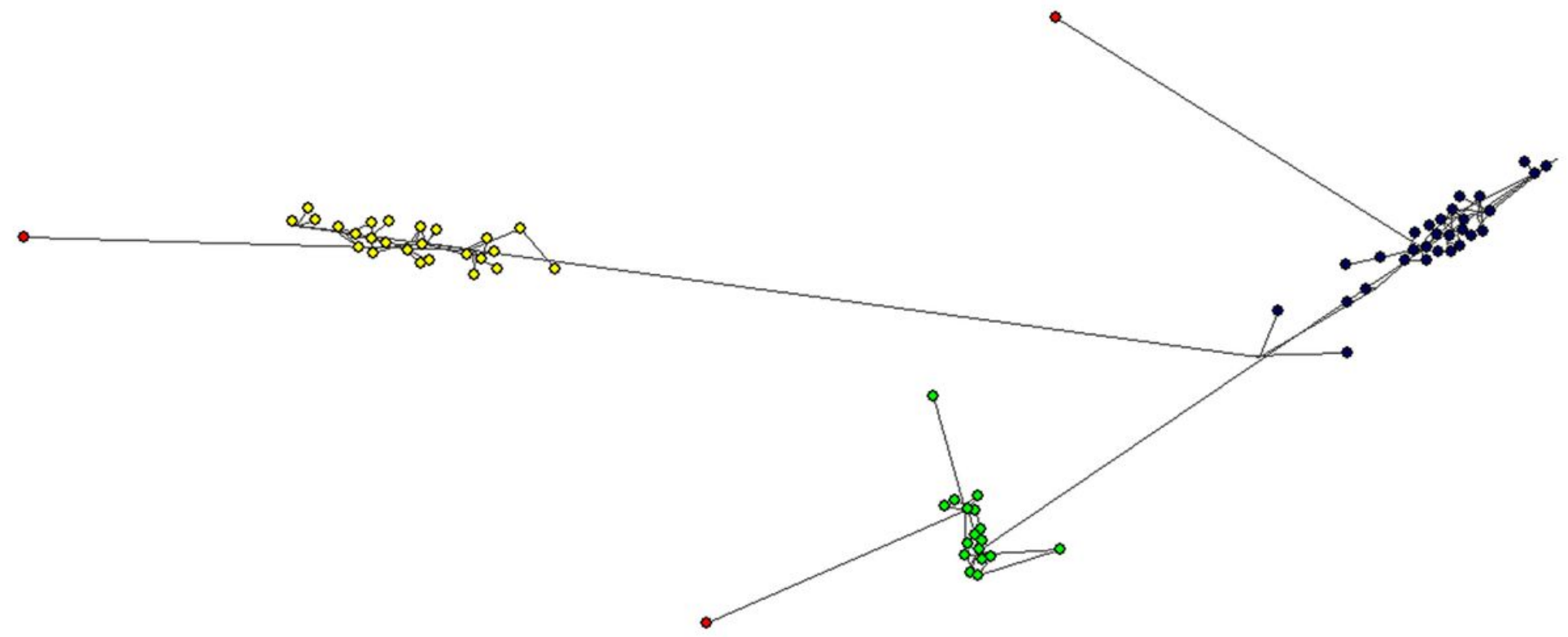

Figure 6

Haplotypes network map showing the threes primers, COI in yellow color, ND4 in blue and, ND5 in green color. The outgroup of Ae albopictus is shown in red. Some haplotypes per each gene were significantly segregated. 


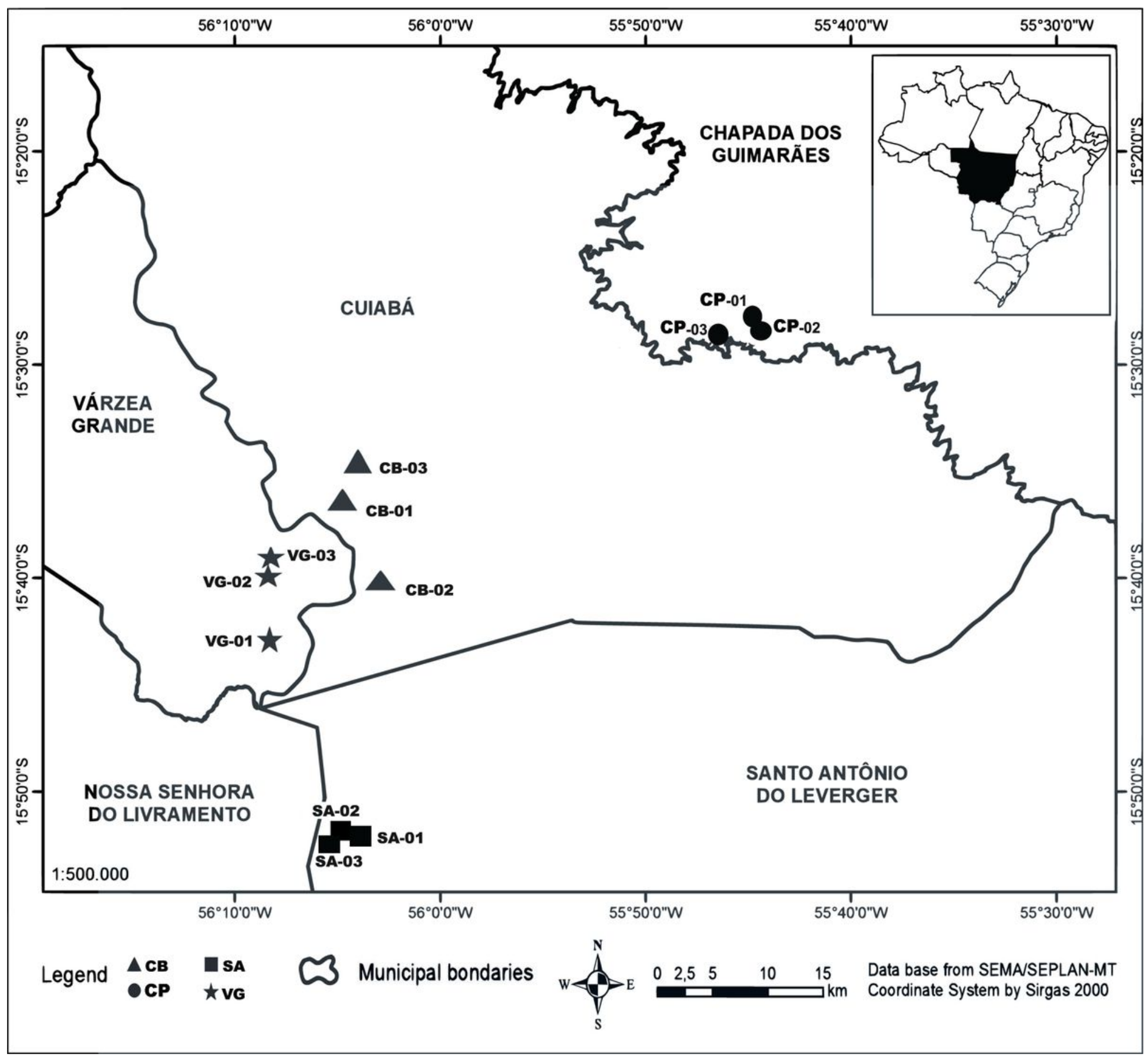

Figure 7

Graphical representation and location of the study area and collection points in the municipalities of Cuiabá (CB), Várzea Grande (VG), Chapada dos Guimarães (CP), and Santo Antônio do Leverger (SA), Mato Grosso. Legend 1. Cuiabá, triangle (CB-01, 02,03), Várzra Grande, star (VG-01, 02, 03) Chapada dos Guimarães, circle (CP-01, 02, 03), and Santo Antônio de Leverger, square (SA-01, 02, 03). 